\title{
Analysis of Environmental Pollution Control Model based on Fuzzy Decision Making
}

\author{
Qinghe Chen, Xin Xia, Zhipeng Wang \\ Liaoning Shihua University, Fushun Liaoning P.R. China \\ E-mail :cqhwzp@163.com,xiaxin_001@163.com,wzpcqh@163.com
}

\begin{abstract}
Practice and theory researchers have an in-depth discussion about the governance model in the face of the increasingly severe environmental pollution problems. This paper established mathematical medel by the fuzzy mathematics theory,proposed that the multiple work mode is needed to realized in environmental pollution control,and forming a polycentric governance network of the government-led,enterprises,social organizations and individual public paiticipation.It proposes that the multiple work model makes a breakthrough to the single subject management model and puts forward to promote multiple work model in real time to control environmental pollution problems effectively from the perspective of fuzzy decision. The paper provides new theoretical basis and reference for the research of environmental governance mode.
\end{abstract}

Keyword: Environmental management ;Governance game; Multivariate-governance; Fuzzy decision

\section{Introduction}

In recent years, environmental pollution is becoming one of the most serious challenges that the government governance faces, and many efforts made to control environmental pollution problems have made by scientific research workers[1,2,3,4]. Although the traditional pattern of the government as the center of administrative management has made certain achievements, it does not contain the deteriorating environmental situation.In the existing pollution control measures, whether the implementation of pollution charge system, apanage management, governance means to strengthen the promotion or the implementation of the laws and regulations, are unsatisfactory[5]. Environment deterioration on the surface is the result of administrative management ,but virtually is the pluralistic subject vacancy problem in the process of political power game[6,7]. Aimed at the defect of traditional top-down administrative management mechanism, Tian[8,9] puts forward the model of multivariate co-govermnet to deal with the environmental pollution problem,break through the limitations of single environmental governance mode ,but it has not established the basis of mathematical model, so it is lack of big data for support. Dou and Yang[10,11] established the fuzzy mathematical model to evaluate water and soil pollution problems, providing new ideas for the research on the problem of environmental pollution. By building the fuzzy mathematical model, we can solve the multi-objective decision problem effectively $[12,13,14]$. In this paper ,the traditional mode of market regulation, government forced mode, and enterprise conscious mode compared with multiple work mode, aimed at the defect of traditional top-down administrative management mechanism, on the basis of a large amount of data statistics, fuzzy uncertainty factors by using the fuzzy quantitative theory, so as to make a comprehensive evaluation. Based on the theory of mathematical deduction, find the optimal solution obtained conclusion. Finally this article thinks: multiple work model for the management of environmental pollution problems will be better than a single model for the management of environmental pollution, finally can realize "good governance" of environmental pollution. 


\section{Properties of Environmental Pollution Control}

To define properties, the management of environmental pollution is not private product, because, in recent years, the leading of it is government but there are business elements, not absolute public products. Therefore, environmental pollution has the properties of quasi-public product. To analyze this property from an economic view, it's hard to build an effective equal-value exchange mechanism between consumers and suppliers. In particular, just rely on the market to adjust the natural resource can lead to "market failure" and only government's adjustment may cause "government failure". To solve this problem, we need to clear the benefit of the management belong to managers or beneficiaries and carry out the principle of "The one who managed, who benefited" in the process.

\section{Effective Game Factors of Environmental Pollution Governance}

The interests are the motivators of the behavior. Different governing subjects focus on different interests, which certainly lead to different control modes. Besides, environmental pollution is an inter-scope problem on the ranges. The differences of the economic developments between various administrative regions result in the ragged extents for environmental pollution control. Considering the economic development, the local governments in economically undeveloped area are reluctant to control pollution. Because no pollution, no tax. Therefore, kinds of reasons result in the interests game among the diversified governing subjects, which block the process of environmental pollution control seriously.

The public interests relate to the environmental interests most. It's not only the practical benefits but also long-time profits.The publicity for the public benefits reflects the multi-element of the governing subjects. Diversified subjects are on behalf of different profits, which leads to profit games between the governments, between the governments and enterprises or the societies.

\subsection{The Game about Interests between Governments}

In China, "Inter-governmental relationships" are referred to diverse district governments horizontally and central authorities and regional governments vertically. Inter-governmental benefits game is based on the development of this kind of inter-governmental relationships [15]. On the one hand, there are benefits games among all kinds of district governments. The partitions of district government are not on the basis of natural resources, but a great deal of districts carry forward their boundaries during the development of history, as a consequence, the phenomenon arises the unfairness of the original distribution of resources. For instance, the districts of the forests and grassland own the strong capacity of self-purification in air pollution. On the contrary, those districts exists so low natural plants cover rates are supposed to put plenty of money into harnessing environment pollution. These kind of original problems in the unfair distribution of resources have trouble with uniformity in performance. If the region is intended to reduce the pressure of environment pollution, it will make the pressure of located environment pollution verge on the neighboring region and lead to their increase in pressure of environment pollution in the immediate vicinity. As a result, the method of releasing environment pollution in the immediate vicinity increases the pressure of environment pollution on the neighboring region instead of taking positive measures to harness located environment pollution, so it results in environment pollution among adjoining areas. On the other hand, between central authorities and regional government exists benefits games. Nowadays, central governments and regional government separately stand for different principal body's benefits games. While their mutual goal exists the uniformity, the regional governments are extremely difficult to start the implementation compared to strategy of central governments. Regional governments must ensure the implementation of central strategy, meanwhile, they are supposed to maximize the benefits in the process of harnessing. Double tasks cause that regional governments have difficulty in implementation in the 
process of harnessing the environment pollution, especially, this kind of difficulty express a sort of extremely "twist" in some undeveloped regions.

\subsection{The Game about Interests between Governments and Enterprise}

In terms of the effects of the environmental pollution control, it is the most efficient for the enterprises to manage by themselves[16]. The enterprises are aware of the sources of the pollution clearly and how to reduce or close them. However, the enterprises are the organizations born to seek profits by nature. Compared with the huge investment for pollution control, the enterprises choose to connive at the pollution surely. Between the personal interests and public welfares, enterprises' choices have never been the latter. Nevertheless, the governments don't let it drift. As the supervision departments carry out the article before says, it is necessary for enterprises to take the responsibility for environmental pollution control during the governments make decisions. Both sides form the interest game on the problem of the environmental pollution control.

In a general circumstance, the enterprise will be able to worry about the effect of operating revenue which caused by the cost of the pollution treatment as well as the social cost if the emissions they hide be found, while the government will consider the income after compelling the enterprise control the pollution. Government will adjust strategy in good time according to the enterprise's action and then control the adverse effect to environment during operating process, when the government out of monitor or the enterprise own feel the cost of pollution was too high, or the enterprise cannot feel pressure when they affect environment. In order to make the enterprise's profit gets to maximization, it will ignore the pollution or lower standard of pollution treatment to make their operating cost get to minimum. In there, local governments own exist a game, pubic interest after pollution or economic interest before.

\subsection{The Game about Interests between Governments and Society}

In the environment protection field, the number of the environmental protection organization which aim at protecting environment rather than make money or exercise administrative right has increased faster in recent years[17]. Facing to inaction or ineffective action of government to improve ecologic environment, there is no doubt that individuals cannot match for the government or enterprise, but only form an environmental protection organization which contains professional staff, advanced technique, economic power and social influence can individuals have equal conversation between deficient to prompt the government and pollution maker be responsible for pollution treatment.

\section{The Establishment of Fuzzy Analogical Reasoning Model}

In view of the above environmental interests game relationship, we can determine the multiple control factors in the process of environmental management. Based on multi center governance theory, fuzzy mathematics model, application of multivariate analysis of environmental pollution, a reasonable mathematical description of the conditional similarity between the objects of the analogy, and provide theoretical support for multi objective decision making, seeking optimal solution, provide the theoretical support for the environment of multi governance model[18,19].

In recent years, facing increasingly severe environmental pollution, the practical workers and theoretical researchers have carried on the thorough discussion to it. Practice has proved, whether the use of market regulation mode, or the government force model, or enterprise consciousness model for ecological environment problems to be governance, they cannot effectively solve the problem of environmental pollution. And multi - governance model of environmental pollution has been favored by many scholars and practitioners. And in recent years it has been put on the agenda. 
The following table shows the change of the national environmental pollutant emissions in 2011-2013.

Table 1. 2011-2013 Years of Environmental Pollution Emissions

\begin{tabular}{|c|c|c|c|}
\hline Index & 2011 & 2012 & 2013 \\
\hline Total discharge of waste water (million tons) & 6591922.44 & 6847612.14 & 6954432.7 \\
\hline Chemical oxygen demand emissions (million tons) & 2499.86 & 2424 & 2352.7 \\
\hline Ammonia emissions (million tons) & 260.44 & 253.59 & 245.66 \\
\hline Total nitrogen emissions (million tons) & 447.08 & 451.37 & 448.1 \\
\hline Total phosphorus emissions (million tons) & 55.37 & 48.88 & 48.73 \\
\hline Oil emissions (ton) & 21012.09 & 17493.88 & 18385.35 \\
\hline Volatile phenol emissions (tons) & 2430.57 & 1501.31 & 1277.33 \\
\hline Lead emissions (Kg) & 155242 & 99358.81 & 76111.97 \\
\hline Mercury emissions (Kg) & 2829.15 & 1223.44 & 916.52 \\
\hline Cadmium emissions (Kg) & 35898.98 & 27249.89 & 18435.72 \\
\hline Total chromium emissions (Kg) & 293166.34 & 190079.08 & 163117.68 \\
\hline Arsenic emissions (Kg) & 146615.97 & 128493.75 & 112230.03 \\
\hline
\end{tabular}

As can be seen from the above table, the 2011-2013 years of the country's emissions of pollutants is a downward trend, the control effect of environmental pollutants can be seen at the same time, attention to the pollutant control mode, making the environment pollution can be effectively controlled.

After being aware of the environmental pollution control problems, the various provinces and cities have taken measures to control the environmental pollution, which is proposed by the multi governance model.

The following picture shows the investment changes in the construction of pollution control projects in various provinces and cities in the 2011-2013:

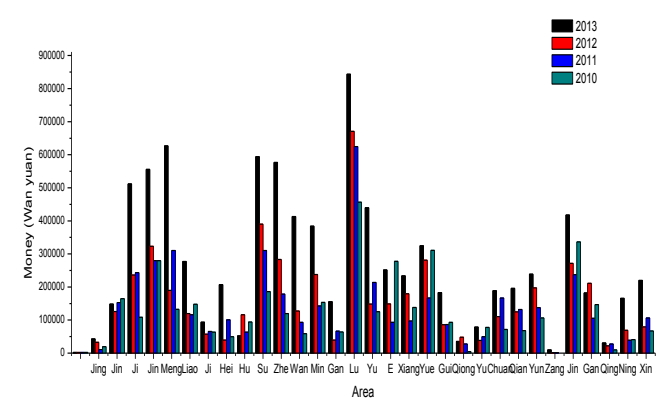

\section{Figure 1.2011-2013 Years of Industrial Pollution Control Investment Statistics}

Can be seen from the picture, the various provinces and cities for the control of environmental pollution have increased year by year, the increase of investment in the governance of environmental pollution is conducive to environmental pollution. 
Based on the theory of multi center governance, this paper constructs a fuzzy relative model, which can provide theoretical support for multiple objective decision making, seek the optimal solution, and then propose the optimal environmental pollution control model in order to form a multi center governance network which is dominated by government, enterprises, social organizations and individuals.

\subsection{Concept Description of Fuzzy Set Theory}

There is no explicit boundary of a subset of the fuzzy sets, which is called a fuzzy subset, which is fuzzy, usually expressed in capital letters with the following wave numbers, like A, $\mathrm{B}$ and so on. In order to express the relationship between an element and a fuzzy subset, Zdahe proposes the concept of "membership degree", the $u_{i}$ of every element in the domain is given a corresponding numerical index which is used to indicate the membership degree of for the $u_{i}$. The membership degree of the element $U_{I}$ for $A$, and satisfy ${ }^{0 \leq \mu_{i A}\left(u_{i}\right) \leq 1}$ perceptibly, $\mu_{A}^{\left(u_{i}\right)}$ is bigger, The higher the membership degree of the element $\mathrm{u}_{1}$ for A.When ${ }^{\mu_{i A}\left(u_{i}\right)=0}$, $\mathrm{U}_{\mathrm{I}}$ certainly does not belong to A; When ${ }^{\mu_{A}\left(u_{i}\right)=1}, \mathrm{U}_{\mathrm{I}}$ must belong to A .In these two cases, The subset is degenerated into a common subset. So ,to expand the absolute membership in the general assembly, So that the elements of the "collection" of the membership by 0 and 1 of these two values, It is extended to any number of units in the unit interval $\{0,1\}$, So it is the key to deal with the problem that it is the key to deal with the problem[20,21].

\subsection{Fuzzy Synthetic Discrimination}

Fuzzy comprehensive evaluation has 3 elements:

(1) Factor set $U=\left\{u_{1}, \ldots, u_{n}\right\}$, is a collection of various factors of the object.

(2) Judge set $\mathrm{V}=\left\{\mathrm{V}_{1}, \ldots \mathrm{V}_{\mathrm{m}}\right\}$, a collection of reviews.

(3) Single factor judgment, that is from the factor set $U$ in a single factor $u_{i}(i=1,2, \ldots, n)$ starting to judge ,determine the degree of membership of the evaluation object to determine the concentration of the elements, The fuzzy set on $\mathrm{V}$ is $\left(r_{i 1}, r_{i 2}, \ldots, r_{i m}\right)$.

So it is from $\mathrm{U}$ to $\mathrm{V}$ on fuzzy mapping: $f: U \rightarrow F(V), u_{i} \mid \rightarrow\left(r_{i 1}, r_{i 2}, \ldots r_{i m}\right)$.

Let $\mathrm{f}$ be a judge function, there are some equationes $f\left(x_{1}, x_{2}, \ldots x_{n}\right)=\sum_{t=1}^{n} a_{t} x_{t}$.

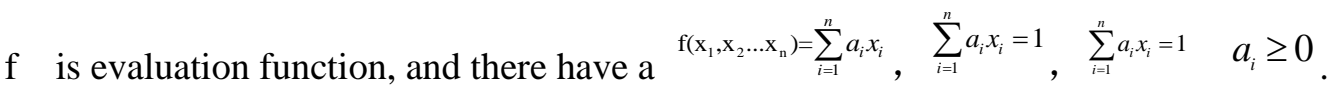

Fuzzy mapping f can identify a fuzzy relationship , that is $R \in \mu_{n^{*} m}$, Called the judging matrix:

$$
R=\left(\begin{array}{ccc}
r & \ldots & r_{1 m} \\
\vdots & \ddots & \vdots \\
r_{n 1} & \cdots & r_{n m}
\end{array}\right) .
$$

\subsection{Application of Fuzzy Sets in this Example}

4.3.1.Raw data preprocessing: Shanghai's economic development is rapid,but the environmental pollution is not very prominent.Guangzhou province is given priority to with manufacturing,and the industry is showing the trend of growth,so the pressure of environment stands out gradually,but it has been controlled well. Zhejiang province is high comprehensive agricultural region in China,and the coastal is opening to the outside world,since the reform and opening up,light manufacturing,processing and manufacturing, and the collective industry have developed rapidly,how to solve the 
environmental pollution we are facing is becoming more and more important.Liaoning province is the northeast old industrial base,develops early and give priority to with heavy industry,so the environmental pollution is very serious, and the governance effect is not very ideal.The four provinces and municipalities all make effort to deal with their environmental pollution and each has its characteristics,so choose it to the depth of theoretical research.

Liaoning Province, Shanghai City, Zhejiang Province, Guangdong Province, province, province, the following table:

Table 2.2011-2013 Emissions of Ammonia Nitrogen (million tons)

\begin{tabular}{|c|c|c|c|}
\hline Area & 2011 & 2012 & 2013 \\
\hline Liaoning Province & 11.11 & 10.75 & 10.33 \\
\hline Shanghai & 5.04 & 4.74 & 4.58 \\
\hline Zhejiang Province & 11.54 & 11.23 & 10.75 \\
\hline Guangdong Province & 23.09 & 22.41 & 21.64 \\
\hline \multicolumn{2}{|c|}{ Data source: National Bureau of Statistics } \\
\hline
\end{tabular}

Set in 2013 the data weight of $0.5,2012$ years of data for the $0.3,2011$ years of the data weight for the 0.2. each year of the province of ammonia emissions data press type integration: $\quad x=\frac{y_{i}}{\sum_{i=1}^{n} y_{i}} \delta_{i}$.

Among this : $y_{i}$ Ammonia emissions from a certain province and city of a year

$$
\sum_{i=1}^{n} y_{i} \text { A total of three years, a total of years in a provincial and municipal }
$$
2011-2013

$\delta_{i}-$ Weight coefficient of one year

According to the original data will be integrated into the original data, get figure 2:

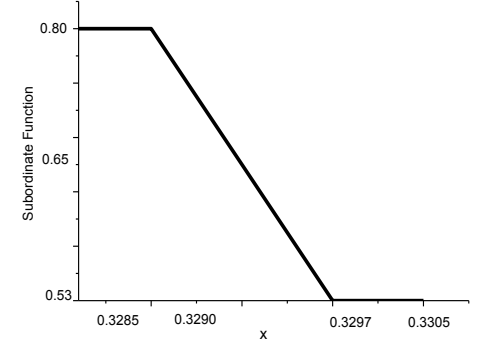

\section{Figure 2.The Degree of Ammonia Nitrogen Emissions}

The statistical results show that the degree of the ammonia nitrogen emissions of the provinces and cities in the 2011-2013 year is stable in the vicinity of 0.80 to 0.53 :

$$
\underset{\sim}{N}(x)=\left\{\begin{array}{lc}
0.80 & 0.3285 \leq x<0.3290 \\
\frac{0.4265-x}{0.1384} & 0.3290 \leq x<0.3297 \\
0.53 & 0.3297 \leq x<0.3305
\end{array} .\right.
$$

Liaoning Province, Shanghai City, Zhejiang Province, Guangdong Province, province, the following table of nitrogen oxide emissions (million tons) by the China national data statistics bureau: 
Table 3. 2011-2013 Annual Nitrogen Oxide Emissions (ton)

\begin{tabular}{|c|c|c|c|}
\hline Area & 2011 & 2012 & 2013 \\
\hline Liaoning Province & 1062816.92 & 1036321.95 & 955381.4 \\
\hline Shanghai & 435400.1 & 401617.86 & 380354.61 \\
\hline Zhejiang Province & 859050.64 & 808848.79 & 752976.23 \\
\hline Guangdong Province & 1388220.35 & 1303428.77 & 1204239.38 \\
\hline \multicolumn{3}{|c|}{ Data source: National Bureau of Statistics } \\
\hline
\end{tabular}

Set in 2013 the data weight of 0.5.2012 years of data for the 0.3,2011 years of the weight of the data for the 0.2. To each year of the provinces and cities of the nitrogen oxide emissions data press type integration: $\sum_{i=1}^{x=\frac{y_{i}}{n} y_{i}} \delta_{i}$.

Among this formula: $y_{i} \_$Nitrogen oxide emissions in a certain province and city

$\sum_{i=1}^{n} y_{i} \ldots$ A total of three years of 2011-2013 in a province and city

$\delta_{i}$ Weight coefficient of one year

According to the original data will be integrated into the original data, get figure 3:

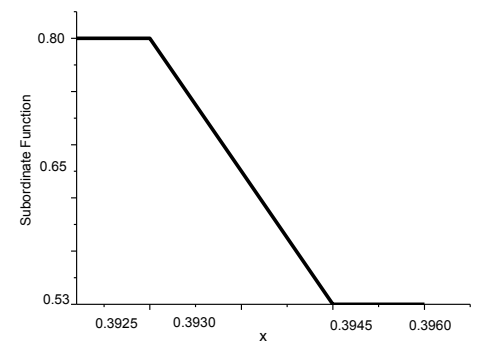

Figure 3.Membership Degree Curve of Nitrogen Oxide Emission

The statistical results show that the membership of the nitrogen oxide emissions in the provinces and cities in the $2011-2013$ is stable at 0.53 to 0.80 :

$$
\underset{\sim}{P}(x)=\left\{\begin{array}{lc}
0.80 & 0.3925 \leq x<0.3930 \\
\frac{0.5325-x}{0.205} & 0.3930 \leq x<0.3945 \\
0.53 & 0.3945 \leq x<0.3960
\end{array} .\right.
$$

Liaoning Province, Shanghai City, Zhejiang Province, Guangdong Province, province, the following table of total phosphorus emissions by the China national data statistics bureau:

Table 4. 2011-2013 Total Phosphorus Emissions (million tons)

\begin{tabular}{|c|c|c|c|}
\hline Area & 2011 & 2012 & 2013 \\
\hline Liaoning Province & 2.78 & 2.76 & 2.68 \\
\hline Shanghai & 0.2 & 0.18 & 0.18 \\
\hline Zhejiang Province & 1.15 & 1.06 & 1.06 \\
\hline Guangdong Province & 2.14 & 2.5 & 2.49 \\
\hline \multicolumn{4}{|c|}{ Data source: National Bureau of Statistics } \\
\hline
\end{tabular}


Set in 2013 the data weight of $0.52,012$ years of data for the $0.3,2011$ years of the weight of the data for the 0.2. To each year of the total phosphorus emissions data press type integration: $x=\frac{y_{i}}{\sum_{i=1}^{n} y_{i}} \delta_{i}$

Among this formula: $y_{i} \_$Total phosphorus emissions from a certain province and city $\sum_{i=1}^{n} y_{i}$ A total of three years of total phosphorus emissions in a province 2011-2013

$\delta_{i} \_$Weight coefficient of one year

According to the original data will be integrated into the original data, get figure 4:

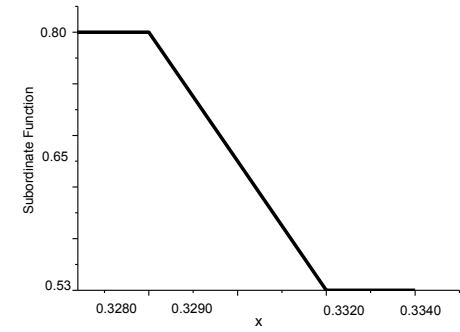

Figure 4. Membership Degree of Total Phosphorus Emissions

The statistical results show that the total amount of the total phosphorus in the provinces and cities in 2011-2013 is stable in the vicinity of 0.80 to 0.53 :

$$
\underset{\sim}{Q}(x)=\left\{\begin{array}{ll}
0.80 & 0.3280 \leq x<0.3290 \\
\frac{0.3845-x}{0.0721} & 0.3290 \leq x<0.3320 \\
0.53 & 0.3320 \leq x<0.3340
\end{array} .\right.
$$

Liaoning Province, Shanghai City, Zhejiang Province, Guangdong Province, province, the following table of smoke (powder) dust emissions (tons) by the China National Bureau of Statistics:

Table 5. 2011-2013 Smoke (powder) Dust Emissions (tons)

\begin{tabular}{|c|c|c|c|}
\hline Area & 2011 & 2012 & 2013 \\
\hline Liaoning Province & 693159.61 & 726257.71 & 670585.64 \\
\hline Shanghai & 89828.4 & 87148.42 & 80924.98 \\
\hline Zhejiang Province & 323320.04 & 254029.81 & 319745.93 \\
\hline Guangdong Province & 324255.94 & 328251.62 & 353967.54 \\
\hline \multicolumn{4}{|r}{ Data source: National Bureau of Statistics } \\
\hline
\end{tabular}

Set in 2013 the data weight of $0.52,012$ years of data for the $0.3,2011$ years of the weight of the data for the 0.2. To each year of the total phosphorus emissions data press type integration:

$$
x=\frac{y_{i}}{\sum_{i=1}^{n} y_{i}} \delta_{i} .
$$

Among them: $y_{i} \longrightarrow$ Total phosphorus emissions from a certain province and city 
$\sum_{i=1}^{n} y_{i} \ldots$ A total of three years of total phosphorus emissions in a province 2011-2013

$\delta_{i} \ldots$ Weight coefficient of one year

According to the original data will be integrated into the original data, get figure 5:

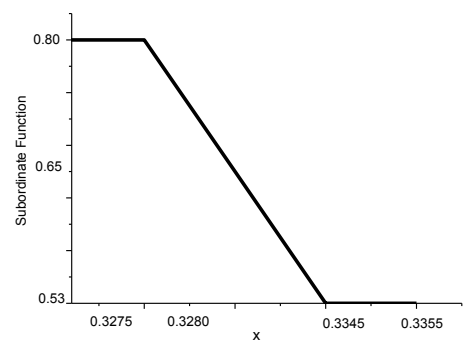

\section{Figure 5. Membership Degree of Total Phosphorus Emissions}

The statistical results show that the total amount of the total phosphorus in the provinces and cities in 2011-2013 is stable in the vicinity of 0.80 to 0.53 :

$$
\underset{\sim}{S}(x)=\left\{\begin{array}{ll}
0.80 & 0.3275 \leq x<0.3280 \\
\frac{0.3674-x}{0.0520} & 0.3280 \leq x<0.3345 \\
0.53 & 0.3345 \leq x<0.3355
\end{array} .\right.
$$

4.3.2.The establishment of fuzzy mathematics model: Design domain $U=\left\{x_{1}, x_{2}, \cdots, x_{n}\right\}$ for alternatives.On $\mathrm{U}$ to determine a fuzzy set $\stackrel{A}{\sim}$, fuzzy mathematical method is used to establish a fuzzy priority relationship in the $\mathrm{N}$ alternatives, and then the order of the advantages and disadvantages of the method is put into using. In comparison with $x_{i}$ and $x_{j}$ by ${ }^{r_{i j}}$, called the selection ratio of $x_{i}$ to ${ }^{x_{j}}$.In spite of the alternatives in contrast to each one has his good points., However, the requirement of selection ratio $r_{i j}$ is

$$
\left\{\begin{array}{l}
r_{i i}=0,0 \leq r_{i j} \leq 1 \quad(i \neq j) \\
r_{i j}+r_{j i}=1
\end{array}\right.
$$

The above conditions show: When compared with $x_{i}$ and $x_{j}$, there are no superiority, Expressed as $r_{i i}=0$; When compared with $x_{i}$ and ${ }^{x_{j}}$, Always Each one has its good points., The excellent composition of both become is 1 , that is $r_{i j}+r_{j i}=1$; When only $x_{i}$ was found to be superior to ${ }^{x_{j}}$ and no ${ }^{x_{j}}$ was found to be superior to $x_{i}$, expressed as $r_{i j}=1, r_{j i}=0$; When $x_{i}$ and $x_{j}$ are not better or worse, expressed as $r_{i j}=r_{i j}=0.5$.

Satisfy (1), there is a $r_{i j}$ matrix: $R=\left(r_{i j}\right)_{n \times n}$.

Is Fuzzy precedence relation matrix, The relationship of the matrix is a fuzzy priority.

Fixed threshold $\lambda \in[0,1]$, have $\lambda$ - intercept array $R_{i}=\left(r_{i j}^{(2)}\right)$.

Among them 
$r_{i j}^{(\lambda)}= \begin{cases}1, & r_{i j} \geq \lambda \\ 0, & r_{i j}<\lambda\end{cases}$

When the data of $\lambda$ is gradually falling from 1 , if the first $R_{\lambda}$, the ${ }^{i_{1}}$ the elements of the elements are equal to 1 of the diagonal elements., and $x_{i}$ is recognized as the first superior object (Not necessarily unique); Then in the R off $x_{i}$ 's row and column, a new (n-1) order fuzzy matrix is obtained., In the same way, the most object is obtained as the second object.; Such recurence, can be all the object to a certain good and bad order.

In view of the above theoretical analysis, based on the integration of the above data, the

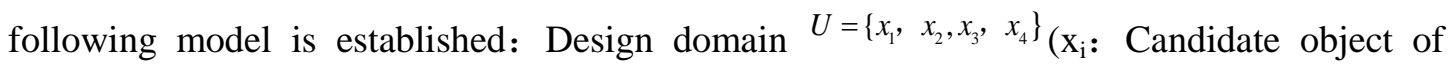
environmental governance model), $\mathrm{A}=$ "Better environmental management model” is a fuzzy set of $\mathrm{U}$, order firstly, and set the rating criteria as follows:

Table 6. Standard Score

\begin{tabular}{ccccc}
\hline Score & optimum & Better & General & inferior \\
\hline Fraction & 10 & 8 & 6 & 4 \\
\hline
\end{tabular}

Table 7. Symbolic Representation

\begin{tabular}{c|c}
\hline $\mathrm{x}_{1}$ & $\begin{array}{c}\text { Shanghai main environmental governance } \\
\text { model }\end{array}$ \\
\hline $\mathrm{x}_{2}$ & $\begin{array}{c}\text { Main environmental governance model in } \\
\text { Guangdong Province }\end{array}$ \\
\hline $\mathrm{x}_{3}$ & $\begin{array}{c}\text { Main environmental governance model in } \\
\text { Zhejiang Province }\end{array}$ \\
\hline $\mathrm{x}_{4}$ & $\begin{array}{c}\text { Main environmental governance model in } \\
\text { Liaoning Province }\end{array}$ \\
\hline
\end{tabular}

Through the above data analysis, it can be known that the distribution of the degree of membership of the environmental pollutant emissions in various provinces and cities from 0.80 to 0.53 in 2011-2013 years, and the distribution of the partition function, as shown in figure 6 :

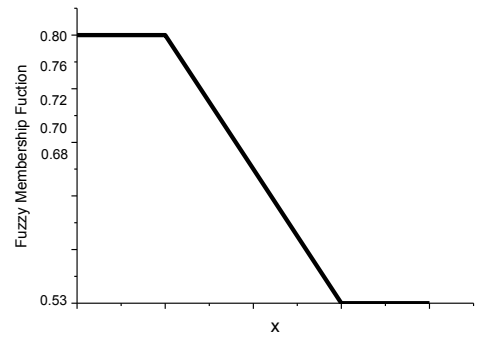

Figure 6. Membership Degree of Environmental Pollutant Discharge

It is a good choice of environmental pollution control mode for the two comparisones, the rules for the: $x_{1} \rightarrow x_{2}$ Based on the first evaluation of the $x_{2}$ as the baseline, the post evaluation of the $\mathrm{x}_{1}$ as the object to carry out the relative score. For example, the government supervision and management mode of the score is 80 points, Then the priority of $x_{2}$ for $x_{1}$ is better than that of $r_{12}=80 / 100=0.8$, corresponding to this, $x_{2}$ preferred to $x_{1}$ is 
$r_{21}=20 / 100=0.2$.

The results obtained by the above method can be expressed in Table 8:

Table 8. Comparison Results

\begin{tabular}{c|c|c|c|c|c|c}
\hline \multirow{4}{*}{$\begin{array}{c}\text { Object } \\
\begin{array}{c}\text { compariso } \\
\mathrm{n}\end{array}\end{array}$} & Optimum & Better & General & Bad & \multirow{2}{*}{$\begin{array}{c}\text { Was } \\
\text { evaluated } \\
\text { by the } \\
\text { target } \\
\text { score }\end{array}$} & $\begin{array}{c}\text { Priority } \\
\text { selection }\end{array}$ \\
\hline & 10 & 8 & 6 & 4 & 80 & 0.80 \\
\hline & 3 & 4 & 3 & - & 72 & 0.72 \\
\hline & 2 & 5 & 3 & 1 & 76 & 0.76 \\
\hline & 1 & 4 & 3 & 2 & 68 & 0.68 \\
\hline & 4 & 2 & 1 & 3 & 70 & 0.70 \\
\hline & - & 2 & 3 & 5 & 53 & 0.53 \\
\hline
\end{tabular}

According to table 8 , the priority selection ratio $\mathrm{R}_{\mathrm{ij}} \quad\left(r_{i j}+r_{j i}=1\right.$, Need $\left.\mathrm{r}_{\mathrm{ii}}=1\right)$ and the condition that it satisfies are given, and the results are shown in Table 9:

Table 9. Priority Ratio Selection Results

\begin{tabular}{c|c|c|c|c}
\hline \multirow{2}{*}{ Object } & \multicolumn{4}{|c}{ Reference } \\
\cline { 2 - 5 } & $\mathrm{x}_{1}$ & $\mathrm{x}_{2}$ & $\mathrm{x}_{3}$ & $\mathrm{x}_{4}$ \\
\hline $\mathrm{x}_{1}$ & 1 & 0.80 & 0.72 & 0.76 \\
\hline $\mathrm{x}_{2}$ & 0.20 & 1 & 0.68 & 0.70 \\
\hline $\mathrm{x}_{3}$ & 0.28 & 0.32 & 1 & 0.53 \\
\hline $\mathrm{x}_{4}$ & 0.24 & 0.30 & 047 & 1 \\
\hline
\end{tabular}

From table 8 the fuzzy precedence relation matrix $R^{(1)}$ can be obtained.:

$$
\boldsymbol{R}^{(1)}=\left(\begin{array}{cccc}
1 & 0.80 & 0.72 & 0.76 \\
0.20 & 1 & 0.68 & 0.70 \\
0.28 & 0.32 & 1 & 0.53 \\
0.24 & 0.30 & 0.47 & 1
\end{array}\right) \text {. }
$$

Take $\lambda=0.70$, to lambda intercept matrix:

$$
\boldsymbol{R}_{0.70}^{(1)}=\left(\begin{array}{llll}
1 & 1 & 1 & 1 \\
0 & 1 & 0 & 1 \\
0 & 0 & 1 & 0 \\
0 & 0 & 0 & 1
\end{array}\right) .
$$

Lambda intercept matrix $\boldsymbol{R}_{0.70}^{(1)}$ elements in the first row of all 1, that only $\mathrm{x}_{1}$ superior degree more than 0.70 , so Shanghai is the main pattern of environmental pollution control of $\mathrm{x}_{1}$ for the first superior object.

The superiority of the object $\mathrm{x}_{1}$ where the rows and columns in the $R^{(1)}$ River, the new fuzzy precedence relation matrix is obtained.: 


$$
R^{(2)}=\left(\begin{array}{ccc}
1 & 0.68 & 0.70 \\
0.32 & 1 & 0.53 \\
0.30 & 0.47 & 1
\end{array}\right)
$$

Take $\lambda=0.63$, there is

$$
\boldsymbol{R}_{0.63}^{(2)}=\left(\begin{array}{lll}
1 & 1 & 1 \\
0 & 1 & 0 \\
0 & 0 & 1
\end{array}\right) \text {. }
$$

Lambda $\mathrm{R}$ intercept matrix elements in the first row of the 1, Guangdong Province should take $\mathrm{x}_{2}$ as the second main environmental governance model is superior. Mark $R^{(2)}$ second superior object $\mathrm{x}_{2}$ where the rows and columns, a new fuzzy preference relation matrix: $R^{(3)}=\left(\begin{array}{cc}1 & 0.53 \\ 0.47 & 1\end{array}\right)$.

$$
\text { Take } \lambda=0.48 \text {, there is } R_{0.48}^{(3)}=\left(\begin{array}{ll}
1 & 1 \\
0 & 1
\end{array}\right) \text {, }
$$

$\mathrm{x}_{3}$ Zhejiang Province, the main environmental governance model can be used as the third superior object.

After determining the matrix of fuzzy priority relationship, the fuzzy relational matrix $\mathrm{R}$ is processed, the membership function of fuzzy set $\stackrel{A}{\sim}$ can be obtained., that is:

$$
\underset{\sim}{A}\left(X_{i}\right)=\underset{j \neq 1}{\wedge} \boldsymbol{r}_{i j}, i=1,2,3, \cdots n, \underset{\sim}{A}=\frac{A\left(x_{1}\right)}{x_{1}}+\frac{A\left(x_{2}\right)}{x_{2}}+\frac{A\left(x_{3}\right)}{x_{3}} \cdots+\frac{A\left(x_{n}\right)}{x_{n}} \text {. }
$$

In this paper, the weighted average method is adopted to determine the $\left.{ }_{\sim}^{A(} \boldsymbol{X}_{i}\right)$, that is:

$$
{ }^{A}\left(x_{i}\right)=\sum_{j=1}^{n} \delta_{j} r_{i}, i=1,2,3, \cdots n \text {, Among them, }\left(\delta_{i}, \delta_{2}, \delta_{3}, \cdots \delta_{n}\right) \text { is a set of weights. }
$$

According to this, the first set of weight is 0.65 , the weight of the second groups is 0.2 , the weight of the third groups is 0.10 , the weight of the fourth groups is 0.05 , and there are some mathematical expressions

$$
\begin{aligned}
& \underset{\sim}{A}\left(x_{1}\right)=0.65 *(1+0.20+0.28+0.24)=1.118 \underset{\sim}{A} \underset{\sim}{A}\left(x_{2}\right)=0.20 *(0.80+1+0.32+0.30)=0.484 \\
& \underset{\sim}{A}\left(x_{3}\right)=0.10 *(0.72+0.68+1+0.47)=0.431 \underset{\sim}{A}\left(x_{4}\right)=0.05 *(0.76+0.70+0.53+1)=0.150 .
\end{aligned}
$$

There is a mathematical expression

$$
\underset{\sim}{A}(\text { Better environmental governance model })=\frac{1.118}{x_{1}}+\frac{0.484}{x_{2}}+\frac{0.431}{x_{3}}+\frac{0.150}{x_{4}} .
$$

In conclusion, according to the size of the membership, four models of fuzzy preference relation: $\mathrm{x}_{1}$-Shanghai majors environmental pollution control mode, $\mathrm{x}_{2}$-Guangdong Province, majors environmental pollution control, $\mathrm{x}_{3}$-Zhejiang Province, majors environmental pollution control mode, and $\mathrm{x}_{4}$-Liaoning Province majors environmental pollution governance prison governor mode.

4.3.3.Interpretation of result: Comprehensive analysis of the above mathematical theory, the fuzzy optimum relation of the four models is: $\mathrm{x}_{1}$ - main environmental pollution control mode in Shanghai City, $\mathrm{x}_{2}-$ Guangdong Province, the main environmental pollution control model, $\mathrm{x}_{3}$ - Zhejiang Province, the main environmental pollution control model, $\mathrm{x}_{4}$ - Liaoning Province, the main environmental pollution control supervision mode.Shanghai City, the main environmental governance model is the best, investigate its reason: Shanghai best 
main environmental governance mode,investigate its reason:Shanghai's main environmental governance mode is a government imposed regulation of macroeconomic regulation and control,market regulation,enterprise should actively control environmental pollutants, and as people's environmental protection consciousness enhancement,more environmental protection organizations' social supervision and so on have made a breakthrough and improvement,make the various power synergy,jointly contribute to environmental pollution control.Practice has proved that the practice of environmental pollution control mode of Shanghai has made the ggovernance's effectiveness of the environmental pollution increase greatly,and has achieved obvious results.

Guangdong Province, the purpose of the operation of enterprises in order to pollute the main business, most of the operating units are to undertake environmental engineering contract, product production and other business oriented, smaller operators. Guangdong province environmental pollution control facilities operation market, Socialized Society Professional development earlier, Guangdong Province in recent years, the main implementation of corporate conscious control mode, Government to promote the operation of the market leading role is not prominent, With the enhancement of the environmental consciousness of the enterprise, Enterprises in the government's macroeconomic regulation and control, actively promote the enterprise's pollution control ability, Initiative to take social responsibility, makes Guangdong Province in recent years, the environmental pollution control has certain effect. However, Market operation of Guangdong province is still in the primary stage, Government supervision of sewage companies is not enough, restrict the operation of professional, market development.

Zhejiang Province, the main environmental pollution control mode for the treatment of environmental pollution is in general, investigate its reason: Zhejiang Province, mainly through the promotion of the general public awareness of environmental protection, to promote the generation of a large number of civil society groups, In order to achieve the purpose of making the social forces to effectively supervise the sewage treatment. However, The extensive economic growth pattern in Zhejiang province has not really changed, increasing pollutant emissions, the most obvious is the abuse of water resources and pollution[20]. Department coordination is not enough, Poor implementation, office procedure 、 Single method. Environmental protection public participation consciousness, Most people lack a clear understanding of the objective situation of the environment. Social forces play a role in supervision, but not obvious.

Liaoning Province, the main environmental pollution control mode for environmental pollution control effect is poor investigate its reason, Have the following two points: One of them: Liaoning province is based on the raw material of the basic industrial base, Metallurgy, petroleum and Chemical and other heavy polluting industries . National policies affect economic development, and then affect the number of industrial pollution sources, the adjustment of industrial structure and the discharge of pollutants have important influence. The relevant policies of the state environmental protection have a direct impact on environmental protection and environmental governance, the cause of the industrial environment and the basis of the development of the environment. Another is Liaoning Province in history was the heavy industry province, "high consumption, high investment, high pollution" was its feature, the traditional economic development model, which is the leading industry of natural resources exploitation, has greatly influenced the ecological environment of Liaoning province.. The over exploitation of history makes it difficult to control environmental pollution.

Can be seen from the above description, Multi governance model has the following advantages: On the one hand is to let all the advantages of environmental pollution control of the main play out. Government led, Market regulation, Social supervision. Attend to each one's own duties, Each in his element, interaction through the above analysis. And according to the conclusions, this paper considers: The model of environmental pollution control should be implemented in a timely. Playing a "combination of environmental pollution 
control", it will require adjustment to the traditional governance model, no longer let a party to bear the main responsibility, but do many things at once, do control process have order, a strategy, governance effect can be expected.

\section{An Effective Way for Environmental Pollution Control: Multivariate Collaborative Work}

\subsection{Clear the Government's Role as a "leading sheep"}

The government as the performer of the public will has the public power and authority by citizens. People trust their government sincerely. Therefore, the government shall be taken as "leading sheep" in the project of environmental pollution which closely link with the people's major interests[22,23]. Before the statement about the interests of the game between the central government or local governments as well as the governments in different administrative areas should be further cooperation and work in accordance with the law. The central government is supposed to do the work about reconciling contradiction and guiding the local government manage the environmental pollution. In addition, they should act the "leading sheep", in the same time, acting the "Shepherd" among the "leading sheep".

\subsection{Play Enterprises" role as the "main force"}

At present, our country is in the transformation of enterprises development. With the international competition increasingly fierce, the enterprise also recognizes that the transformation must be carried out. The focus on enterprise transformation is to improve the competitiveness of science and technology as well as reduce the energy consumption. The two points are the inevitable requirement for enterprise to earn more in the future. At the same time, the competition of enterprises is also deep into the field of social credit. Consumers have gradually begun to pay more attention to the moral conscience, a responsible enterprise always can gain recognition in the psychological and behavior, that's an important factor to promote the company get a well-known brands. Therefore, enterprises in the production process are supposed to reduce pollution emissions as well as manage the pollution. It's better for the doer to undo what he has done. The enterprise should play an important role in reducing the pollution, no more than the polluters to know how to control environmental pollution.

\subsection{Promote Social Organization's role as the "plaintiff"}

Article 58 of the environmental law in accordance with the law in the civil affairs department under the people's government at or above the level of district-constituted municipalities registration, specializing in environmental protection public welfare activities for five consecutive years and no record of illegal social organization" environmental public interest litigation could be made. That ensured that the plaintiff qualification of social commonweal organization. There was relatively few case of litigation for public interests in environmental protection in our country, thus, it is worth to propagate The Environment Law further to increase winning rate of litigation for public interests in environment and encourage to play a plaintiff role going a step further.

\subsection{Strengthen Masses' role as the "supervisor"}

People are the direct beneficiaries of environmental pollution control. Because environmental pollution is the biggest harm to people's body. Besides, in the long run, it is a huge damage to the resources. The people in various places of our country can always find the pollution. To strengthen the supervision of the people to the enterprise, the government should give people guidance, telling people how to supervise. Supervision has the way, the complaint has the door, government support and people supervise. Our masses participate in the environmental pollution control is the best way to reduce the cost of environmental pollution control. 


\section{Conclusion}

Environmental pollution control has a quasi-public product qualities,analysis of the multi-subject interests showed that the single governance model is not desirable and the use of fuzzy mathematical theory analysis got a conclusion that the scientific nature and necessity of multi-governance. The so-called multi-governance is to let the main body of environmental pollution control combined in a more scientific and reasonable way, both to strengthen the previous government leading role and market regulation, but also to let the social environment protection organizations play their role in environmental pollution, at the same time, let people play a supervisory role. The application of fuzzy mathematics theory is not only have demonstrated the necessity of multi-governance, but also analyzed the responsibility of the main body and how to strengthen cooperation between the main body, common governance environmental pollution. As far as I'm concerned, based on the analysis of environmental pollution control through a fuzzy decision-making, it is not a rejection of the past governance, but "through the multi-governance model of governance remold the various system internally and externally and the original and new governance of the main body "proposed a more efficient environment of "good governance".The paper is based on big data to establish mathematical model by fuzzy mathematics, theoretically determine the superiority of multiple work mode control environmental pollution problems,and provides theoretical reference for subsequent model of pollution control research work.But due to the limited scope of research,this paper can not list all conditions about environmental pollution in the process of discussing,the following work based on this subject should expand the scope to research further.

\section{Acknowledgements}

We thank the anonymous reviewers for the valuable comments. This research is supported by the periodic achievement of Liaoning social science planning fund project (Project No.L14BJY028).

\section{References}

[1] WU Xiao-jian,XU He-ping.Synergic and Multiple Governance: Solution to the Dilemma of Collective Action in Water Pollution Control. Journal of Anhui Radio\&TV University.(2013),Vol.3,pp.13-17.

[2] ZHANG Xinwen, ZHANG Guolei.Collaborative Governance: the Innovation Governance Model of the Group Events in Environment. Journal of Shaartxi Academy of Governance.(2013),Vol.32,pp.107-112.

[3] Gao Jin-hong.Strategies of Urban Environmental Pollution. Resources and Environment.(2016),Vol.42,pp.215.

[4] HE Jun,LIU Qiming,TANG Shuyi.Environmental Pollution Control Investment and Environmental Pollution-Theoretical and Empirical Research Based on Endogenous Growth. Journal of Dalian University of Technology （Social Sciences）.(2016),Vol.37,pp.12-18.

[5] DONG Wen-fu,FU Deqian,NU Liya.Analysis of Development of the Investment in the Treatment of Environmental Pollution in China. Environmental Mnitoring in China.(2008).Vol.24,pp.87-89.

[6] Lou Shuwang.Environmental Governance:the Responsibility of the Local Government and Restrictive Factors.CHINESE PUBLIC ADMINISTRATION.(2016).Vol.3,pp.48-53.

[7] TAN Jing-bo.Government and People Cooperation Problems In Environmental Pollution Control Research In China. Theoretic observation .(2014).Vol.24,pp.28-30.

[8] TIAN Qian-shan .Comparative Analysis of Several Eco-environment Governance Model. Journal of Shaartxi Academy of Governance.(2012),Vol.26,pp.52-57.

[9] TIAN Qian-shan.The Ecological Environment Of Multiple Work Mode:The Concept and Construct.ADMINSTRATIVE TRIBUNE.(2013),Vol.3,pp.94-99.

[10] DOU Lei, ZHOU Yongzhang, WANG Xuri, YANG Zhiojun, PENG Xianzhi, LI Xiu-juan.Improvement and Application of a Fuzzy Mathematical Model for Assessment of Heavy Metal Pollution in Soil. Chinese Journal of Soil Science .(2007).Vol.38,pp.101-105.

[11] YANG Haijiang,WANG Jianyu,SHI Lei,ZHAO YunPeng. Application of Fuzzy Mathematical Method in Assessment of Lo River Water Quality. Modern agriculture department.(2016).Vol.10,pp.178-180.

[12] YAO Min, HUANG Yan-jun.Research on Methodology of Fuzzy Decision Making. Systems Engineering-Theory \& Practice.(1999).Vol.19,pp.1-7.

[13] GAO Zhi-nian, XING Han-cheng.With Fuzzy Mathematical Methods To Solve Multi-objective Decision-making Problem. Military Operations Research and Systems Engineering. (2001).Vol.4,pp.47-50.

[14] RAO Cong-jun,XIAO Xin.The Fuzzy Mathematics Method Of Multi-objective Decision Problem.Journal of WuHan University of Technology.(2006).Vol.30,pp.700-703. 
[15] QIU Gang-zheng,CHANG An,GAO Qi.Several Kinds of Ecological Environmental Governance Mode of The Comparative Analysis.8(2014).

[16] CAO Jiao-xing.Behaviour Logic and Implementation Mechanism Of The Ecological Environment Of Collaborative Governance. ENVIRONMENT AND SUSTAINABLE DEVELOPMENT .(2015). Vol.2,pp.67-70.

[17] LI Wen-yu.Fuzzy Mathematics Method Is Applied To Evaluation Of Hechi City Atmospheric Environment Quality. LOW CARBON WORLD .(2016).Vol.9,pp.220.

[18] FANG Jian-wei.Mathematical Modeling Optimization Theory. Journal of Xianning Ulliversity (2011),Vol.31,pp.167-168.

[19] GAO Zhi-nian, XING Han-cheng.With Fuzzy Mathematical Methods To Solve Multi-objective Decision-making Problem. Military Operations Research and Systems Engineering. (2001).Vol.4,pp.47-50.

[20] Jiang Xiaoqing, Lu Minghao, Lu Yuanyuan, Wang Huan, Jiao Maomao. Analysis and assessment of urban air quality based on fuzzy mathematics.ENVIRONMENT \&DEVELOPMENT(2015).Vol.27,pp.56-59.

[21] YANG Haijiang,WANG Jianyu,SHI Lei,ZHAO YunPeng. Application of Fuzzy Mathematical Method in Assessment of Lo River Water Quality. Modern agriculture department.(2016).Vol.10,pp.178-180.

[22] YANG Dan.Sun Hongkun. A Research on the Judicial Protection Mechanism of " the Government of Five Water " in Zhejiang Province.JOURNAL OF EMCC,(2015),Vol.25,,pp.24-27.

[23] ZHOU Qi,HUANG Shao-qian.Based On The Fuzzy Comprehensive Evaluation Of Heavy Metals Pollution In Cities. Journal of Seeking Knowledge Guide.(2016).Vol.3,pp.77-78.

\section{Authors}

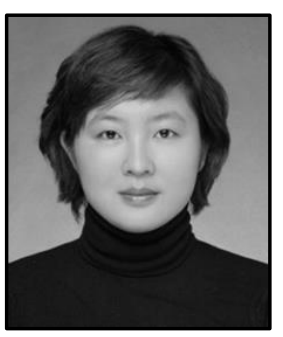

Qinghe Chen, she received the BSc(2005) degree in finance from Liaoning University, the MSc(2010) degree in Economic Law from Dongbei University of Finance and Economics. Her current research interests include legal regulation, public policy and statistical data analysis.

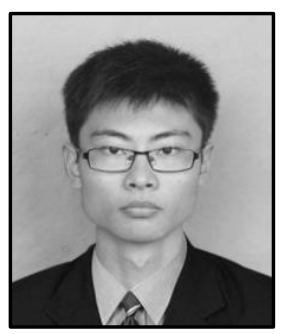

Xin Xia, he is studying at Liaoning Shihua University majoring in supplied chemistry. His current research interests include the fuzzy mathematics of research and statistical data analysis.

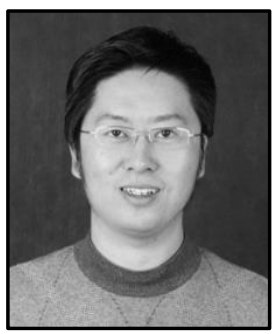

Zhipeng Wang, he obtained his BSc(2005) degree in Law from Jilin University, the $\operatorname{MSc}(2008)$ degree in Economic Law from Dongbei University of Finance and Economics, the DSc(2012) degree in Economic Law from Jilin University. His current research interests include legal regulation, environmental pollution control. 